\title{
Optimizing future planning in Parkinson disease: suggestions for a comprehensive roadmap from patients and care partners
}

\author{
Sarah R. Jordan ${ }^{1}$, Benzi Kluger ${ }^{2}$, Roman Ayele ${ }^{3,4}$, Adreanne Brungardt ${ }^{1}$, Anne Hall ${ }^{5}$, Jacqueline Jones ${ }^{4}$, \\ Maya Katz ${ }^{6}$, Janis M. Miyasaki ${ }^{7}$, Hillary D. Lum ${ }^{1,8}$ \\ ${ }^{1}$ Division of Geriatric Medicine, Department of Medicine, University of Colorado Anschutz Medical Campus, Aurora, Colorado, USA; ${ }^{2}$ Departments \\ of Neurology and Medicine, University of Rochester Medical Center, Rochester, NY, USA; ${ }^{3}$ Denver-Seattle Center of Innovation, Rocky Mountain \\ Regional Veterans Affairs Medical Center, Aurora, CO, USA; ${ }^{4}$ College of Nursing, University of Colorado Anschutz Medical Campus, Aurora, CO, \\ USA; ${ }^{5}$ Research Stakeholder, University of California, San Francisco, CA, USA; ${ }^{6}$ Movement Disorders and Neuromodulation Center, University of \\ California, San Francisco, CA, USA; ${ }^{7}$ Division of Neurology, University of Alberta, Edmonton, Alberta, Canada; ${ }^{8}$ VA Eastern Colorado Geriatric \\ Research Education and Clinical Center, Aurora, CO, USA \\ Contributions: (I) Conception and design: All authors; (II) Administrative support: SR Jordan, A Brungardt; (III) Provision of study materials or \\ patients: B Kluger, M Katz, JM Miyasaki; (IV) Collection and assembly of data: SR Jordan, A Brungardt, J Jones; (V) Data analysis and interpretation: \\ All authors; (VI) Manuscript writing: All authors; (VII) Final approval of manuscript: All authors. \\ Correspondence to: Hillary D. Lum, MD, PhD. Associate Professor of Medicine, Division of Geriatric Medicine, University of Colorado School of \\ Medicine, 12631 E. 17th Ave B-179, Aurora, CO 80045, USA. Email: Hillary.lum@cuanschutz.edu.
}

Background: Living with Parkinson disease (PD) is complicated by an unpredictable disease course which can delay planning for future needs. This study explores patient and care partner needs related to future planning using a palliative care framework with physical, psychological, social, cultural, end-of-life, and ethical aspects of care in PD to guide analysis.

Methods: Secondary analysis of patient and care partner interviews from a randomized clinical trial comparing interdisciplinary outpatient palliative care versus standard care for individuals with PD and care partners in an academic setting. Sixty participants were interviewed (30 patients and 30 care partners) about needs related to future planning. Team-based thematic analysis was used to identify key themes.

Results: Many care partners and patients living with PD described a desire for information about what to expect and how to plan for the future. Participants posed multiple questions about PD progression and devised the metaphor of a "roadmap" as a guide for decision making and planning. When exploring the concept of a PD roadmap, five themes emerged: (I) desire for a comprehensive tool for future planning, such as a roadmap; (II) care partner preferences for specific future planning; (III) PD-related life changes as opportunity for future planning and decision-making; (IV) cues from family, peers, and medical professionals about "location" on the roadmap; and (V) opportunities and challenges to integrating a PD roadmap into patient-centered care.

Conclusions: Patients and care partners described key needs related to future planning that can inform a comprehensive roadmap to assist with education, communication, and decision making. A roadmap tool can promote individualized anticipatory guidance and multidimensional shared decision-making discussions between patients, care partners, and the healthcare team related to PD progression.

Keywords: Caregiver; decision-making; palliative care; Parkinson disease (PD); qualitative

Submitted Aug 16, 2019. Accepted for publication Sep 10, 2019.

doi: 10.21037/apm.2019.09.10

View this article at: http://dx.doi.org/10.21037/apm.2019.09.10 


\section{Introduction}

Parkinson disease (PD) has significant impact on patient and care partner quality of life, function, and overall well-being. Core palliative care issues, such as those related to support for families and care partners, attention to spiritual wellbeing, discussions about prognosis, and planning for progressive disability, are not systematically addressed (1-3). A patient and family's understanding of serious or chronic illnesses, including how the disease is changing over time, can affect how patients and care partners navigate disease management, quality of life preferences, and future planning (4). Given that PD is the $14^{\text {th }}$ leading cause of death in the US and is associated with significant symptom burden and dementia, there is a clear need for clinical tools that help patients and families throughout the disease trajectory $(5,6)$.

Palliative care approaches can address the individual needs of patients and care partners related to living with serious illness (7). The National Consensus Project Clinical Practice Guidelines for Quality Palliative Care (NCP Guidelines) describes seven domains of palliative care which are highlighted in Figure 1 (8). While recent studies have described the opportunity to integrate palliative care into routine PD neurological care (9-11), there is a need to more specifically understand patient and care partner preferences for multidimensional and comprehensive future planning across the PD illness trajectory, and the extent to which patient and care partner needs are effectively addressed by exploring the palliative care domains.

$\mathrm{PD}$, a progressive neurodegenerative disease, has limited evidence-based or patient and family co-created educational materials to provide anticipatory guidance about expectations as the disease progresses $(12,13)$. The purposes of patient educational materials are to facilitate education, shared decision making, and communication (14). A persistent message of PD clinical care, educational resources, and support groups is that each person is unique, and that no two illness trajectories are alike. While this may be true, it is not helpful to individuals trying to prepare for the future. Existing information sources are generally very extensive and difficult for patients and families to use. Currently, there are no comprehensive future planning tools for use in clinical practice that utilize a multidimensional palliative care approach for PD.

The lack of anticipatory guidance for illness trajectories may be a source of caregiver burden. A recent study of care partners of persons with dementia found that uncertainty around the future was one of three burden factors, along with direct impact of caregiving and frustration or embarrassment (15). Therefore, in this current study, we engaged a Parkinson Disease Patient and Family Advisory Council as research stakeholders (16), and together identified the need for education about the PD illness trajectory. Our primary objective was to explore patient and care partner perspectives on anticipatory guidance for what to expect and how to plan for the future as the illness progresses. We used a qualitative descriptive approach to conduct an in-depth exploration of the concept of a "roadmap", a metaphor that resonated with patients and care partners within a large randomized clinical trial of palliative care for PD. After describing the importance of a roadmap for comprehensive future planning in $\mathrm{PD}$, this study highlights patient and care partner perspectives related to "What should be on the roadmap? Where am I/we on the roadmap? Who can I ask for support?", framed by the National Consensus Project Clinical Practice Guidelines for Quality Palliative Care.

\section{Methods}

\section{Design}

This qualitative descriptive study is a secondary analysis of a large, multi-site randomized clinical trial of interdisciplinary outpatient neuropalliative care compared to standard neurological care for individuals with PD and care partners, which has been described in detail $(17,18)$. The current study draws from semi-structured interviews with $30 \mathrm{PD}$ patients and 30 care partners at 12 months since enrollment in the trial. The research was conducted among 210 patients with symptomatic $\mathrm{PD}$, and care partners if present, who were all recruited from the University of Colorado Hospital Movement Disorders Clinic (Aurora, Colorado, USA), Kaye Edmonton Clinic at the University of Alberta (Edmonton, Alberta, Canada), and University of California San Francisco Parkinson Disease Supportive Care Clinic (San Francisco, California, USA). Patients and their care partners, when identified, were randomized to usual care, including a primary care provider and neurologist, or to palliative care, including an outpatient interdisciplinary palliative care team consisting of a neurologist with palliative care experience, a nurse, a social worker, and a chaplain. This study was approved by the Institutional Review Board at each site. All participants provided written informed consent. Participants were not compensated for interviews but did receive reimbursement for participating 


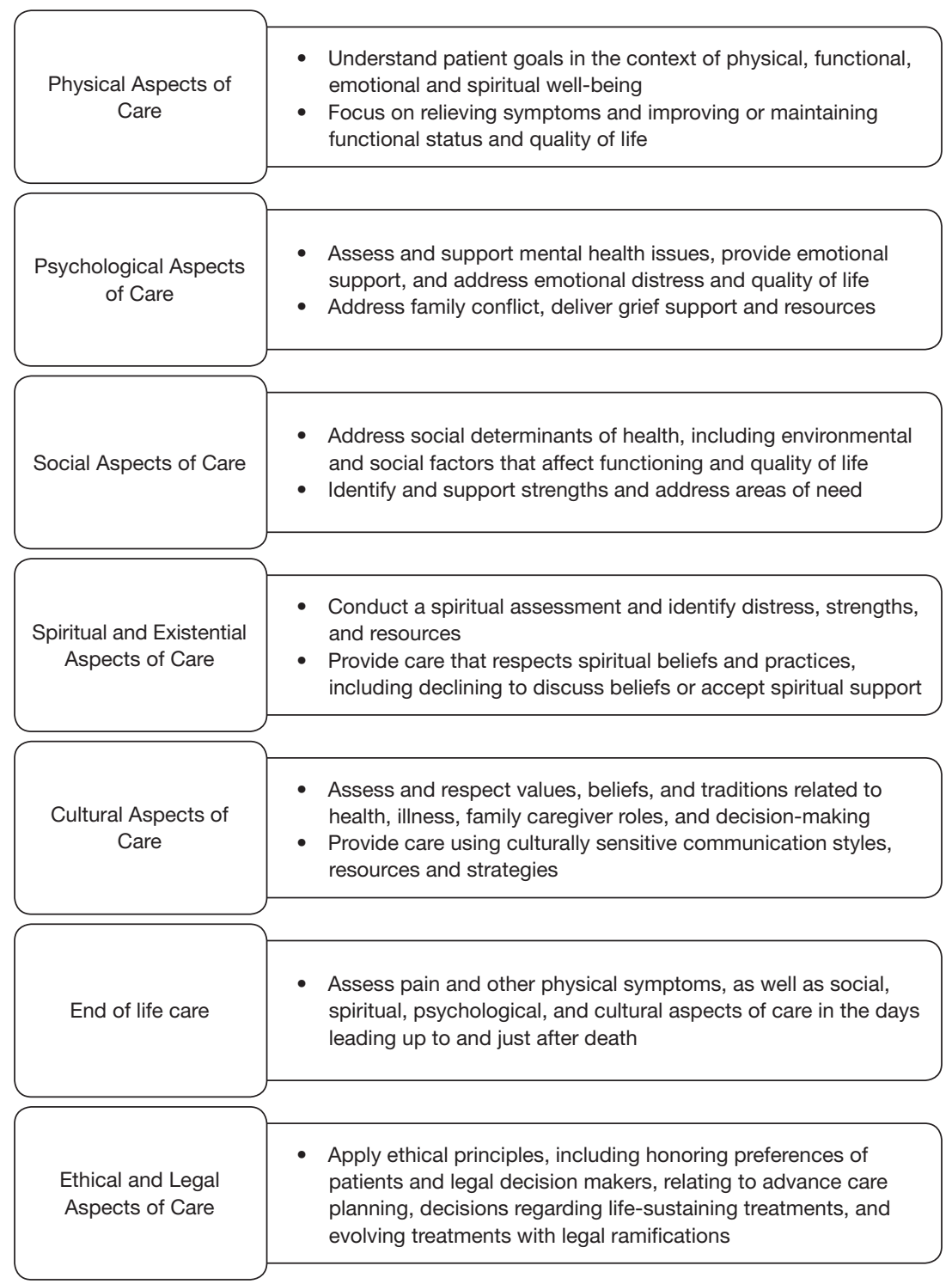

Figure 1 Brief descriptions of key domains of quality palliative care, adapted from the National Consensus Project Clinical Practice Guidelines for Quality Palliative Care (8).

in the RCT. The clinical trial identifier is NCT02533921.

\section{Participants}

Patients were included if they were fluent in English, over age 40, and met UK Brain Bank criteria for a diagnosis of probable PD (19). Patients were at high risk for poor outcomes based on the Palliative Care Needs Assessment Tool (20), modified for PD. Care partners were identified by asking the patient who assists them the most with their PD. Interviews were conducted between September, 2017, and March, 2018. During this period, 81 patients and 56 care partners had reached the study 12 -month time point. The research team planned a goal of 60 interviews from 137 participants available at the time of our qualitative study to ensure maximum variation from all three study locations, both study arms, all genders, and both respondent types (patient and care partner). Potential interview participants were also chosen to have diverse perspectives such as patients who did and did not have a care partner; care partners of persons with dementia; and participants (both patients and care partners) who are affected by early vs more 
advanced PD based on Hoehn and Yahr staging. Purposeful sampling was guided by input from site investigators $(21,22)$, who defined whether patients or care partners were no longer able to participate in the interview because it could be potentially burdensome or they had significant executive problems, or because they had moved or had died. Patients or care partners were interviewed separately.

\section{Research question and data collection}

Our main study question explored the desire for help or guidance related to comprehensive future planning needs related to living with $\mathrm{PD}$ as a patient or care partner. We developed a semi-structured interview guide (see Supplement 1) that was revised iteratively with input from the Parkinson Disease Patient and Family Advisory Council and a multidisciplinary scientific advisory board with expertise in movement disorders and palliative care. Interview topics included future planning, planning in the context of potential cognitive changes or dementia, communication about the future with spouses/care partners/family members, and perceptions of illness progression. As the metaphor of a roadmap emerged, it was re-contextualized in subsequent interviews and explored in-depth. To enable participants to describe their future planning needs and preferences in an open-ended fashion, interviewers did not specifically probe for the seven palliative care domains from the NCP Guidelines (physical, psychological, social, spiritual, cultural, end-of-life, and ethical/legal care). Interviews lasted up to 2 hours, were digitally recorded, and were conducted by research team members who were not part of the participants' clinical team. Interviews were digitally recorded and professionally transcribed. Respondents provided demographic information both on themselves and their associated study partner (except for patients without a care partner). Less than $5 \%$ of demographic data is missing.

\section{Data analysis}

This analysis uses an iterative, team-based, inductive and deductive approach to identify key themes (23). Transcripts were de-identified with the exception of participant type (patient or care partner), study site, and study arm (palliative care or standard care) and read inductively individually by each team member. We defined and agreed upon a codebook, and three authors each coded roughly onethird of the data (with double coding to enhance reliability of code use over $25 \%$ of transcripts). Team members met regularly to discuss emerging themes, reach consensus, and organize meaningful content and relationships between codes into thematic schemes which reflected participant perspectives and experiences (24). The deductive approach focused on conceptualizing and organizing key concepts or topics for a PD-specific comprehensive future planning tool (a "roadmap") using the NCP Guidelines as a framework. We tracked analytic decisions on emerging themes throughout analysis. We conducted triangulation with the larger multidisciplinary team and the Parkinson Disease Patient and Family Advisory Council to increase validity, as a measure of quality in qualitative research $(25,26)$. Informational saturation was reached prior to reaching the goal of 60 participants, but all interviews were thoroughly analyzed (24,27). We used Atlas.ti (Version 7.5.18) software for data management.

\section{Results}

Thirty patients and thirty care partners were interviewed, evenly split across both standard care and palliative care arms and proportionate across all three study sites (Table 1). Most care partners were female $(77 \%)$ and the majority of patients were male $(63 \%)$. Most interviewees were Caucasian, with an average current age of 67 and average age at diagnosis of 57 years old.

Patients and care partners described the metaphor of a PD roadmap that could help with anticipating future needs and raising appropriate questions for discussion among patients, care partners, and the healthcare team. Five key themes emerged from participants: (I) desire for a comprehensive tool for future planning, such as a roadmap, (II) care partner preferences for specific future planning, (III) PD-related life changes as opportunity for future planning and decision-making, (IV) cues from family, peers, and medical professionals about "location" on the roadmap, and $(V)$ opportunities and challenges to integrating a PD roadmap into patient-centered care.

\section{Theme 1-desire for a comprehensive tool for future planning, such as a roadmap}

When initially asked about future planning related to living with $\mathrm{PD}$, patients and care partners recognized the difficulty of knowing what questions to ask or what information is important. In early interviews, as participants considered what would be important to them related to 
Table 1 Demographic characteristics

\begin{tabular}{|c|c|c|}
\hline Characteristic & $\begin{array}{c}\text { Patients }(n=30) \\
n[\%]\end{array}$ & $\begin{array}{l}\text { Care partners } \\
(\mathrm{n}=30), \mathrm{n}[\%]\end{array}$ \\
\hline Age, years [SD] & $66[8]$ & $68[7]$ \\
\hline $\begin{array}{l}\text { Age at time of PD } \\
\text { diagnosis, years [SD] }\end{array}$ & $57[8.4]$ & $\mathrm{N} / \mathrm{A}$ \\
\hline Female sex & $11[37]$ & $23[77]$ \\
\hline \multicolumn{3}{|l|}{ Race/ethnicity } \\
\hline White & 27 [90] & 27 [90] \\
\hline Black & $1[3]$ & $0[0]$ \\
\hline Asian & $2[7]$ & $2[7]$ \\
\hline Hispanic & $0[0]$ & $0[0]$ \\
\hline \multicolumn{3}{|l|}{ Site } \\
\hline University of Alberta & $11[37]$ & $12[40]$ \\
\hline University of Colorado & $11[37]$ & $9[30]$ \\
\hline $\begin{array}{l}\text { University of California } \\
\text { San Francisco }\end{array}$ & $8[27]$ & 9 [30] \\
\hline \multicolumn{3}{|l|}{ Study arm } \\
\hline Palliative care & $14[47]$ & 20 [67] \\
\hline Standard care & $16[53]$ & 10 [33] \\
\hline \multicolumn{3}{|l|}{ Marital status } \\
\hline Married & 25 [83] & 28 [93] \\
\hline Single & $1[3]$ & $2[6.7]$ \\
\hline Divorced/widowed & $4[13]$ & $0[0]$ \\
\hline \multicolumn{3}{|l|}{ Education } \\
\hline High school or less & $2[7]$ & $5[17]$ \\
\hline $\begin{array}{l}\text { Bachelor degree or some } \\
\text { college }\end{array}$ & $12[40]$ & $14[47]$ \\
\hline Post graduate & $16[53]$ & $11[37]$ \\
\hline \multicolumn{3}{|l|}{ Income } \\
\hline Under $\$ 49,000$ & $4[16]$ & N/A \\
\hline$\$ 50,000-\$ 99,999$ & $15[60]$ & $1[50]$ \\
\hline More than $\$ 100,000$ & $6[24]$ & $1[50]$ \\
\hline $\begin{array}{l}\text { Disease duration }{ }^{\dagger} \text { (months, } \\
\mathrm{SD} \text { ) }\end{array}$ & $110[77]$ & $\mathrm{N} / \mathrm{A}$ \\
\hline $\begin{array}{l}\text { Received deep brain } \\
\text { stimulation surgery }\end{array}$ & $4[13]$ & $5[17]$ \\
\hline
\end{tabular}

Table 1 (continued)
Table 1 (continued)

\begin{tabular}{|c|c|c|}
\hline Characteristic & $\begin{array}{c}\text { Patients }(n=30) \\
n[\%]\end{array}$ & $\begin{array}{l}\text { Care partners } \\
(\mathrm{n}=30), \mathrm{n}[\%]\end{array}$ \\
\hline \multicolumn{3}{|l|}{ Hoehn and Yahr ${ }^{\dagger}$} \\
\hline Level I & 10 [33] & $8[27]$ \\
\hline Level II & $11[37]$ & 9 [30] \\
\hline Level III & $5[17]$ & $6[20]$ \\
\hline Level IV & $1[3]$ & $4[13]$ \\
\hline Level V & $1[3]$ & $3[10]$ \\
\hline $\begin{array}{l}\text { Montreal Cognitive } \\
\text { Assessment, mean }(\mathrm{SD})^{\dagger}\end{array}$ & 26 [3.2] & $24[4.7]$ \\
\hline \multicolumn{3}{|l|}{ Care partner type } \\
\hline Spouse or partner & 19 [63] & 27 [90] \\
\hline Child or other & $3[10]$ & $3[10]$ \\
\hline No care partner & $8[27]$ & $\mathrm{N} / \mathrm{A}$ \\
\hline $\begin{array}{l}\text { Care partner lives in same } \\
\text { household as patient }\end{array}$ & 21 [95] & 28 [93] \\
\hline Involved in support groups & $17[57]$ & 19 [63] \\
\hline $\begin{array}{l}\text { Duration of caregiving [SD], } \\
\text { months }\end{array}$ & $\mathrm{N} / \mathrm{A}$ & $80[46]$ \\
\hline
\end{tabular}

living with $\mathrm{PD}$, the metaphor of a roadmap emerged and was explored in-depth. When considering the future, patients and care partners had several questions related to how their PD would change over time and how quickly it would change (i.e., "speed" of PD illness trajectory). These questions reflected a desire for information that would address their personal experiences compared to an expected PD trajectory and/or the experiences of others. In their own words, patients identified the concept of a roadmap: "A roadmap, or even things we should be looking at in end stage, would be helpful" (standard care). Another patient in standard care described specific questions a roadmap might address, stating,

"[A roadmap would show] where the 'rest stops' are, [because] not all symptoms are the same. Where would the [rest stops] be? How much longer is it going to take it for me to get there? Don't we have stuff that we can look forward to? That's what I'm hoping for so that maybe we get control over it. How else would you know?" 
Table 2 Frequent questions from patients and care partners related to Parkinson disease and future planning

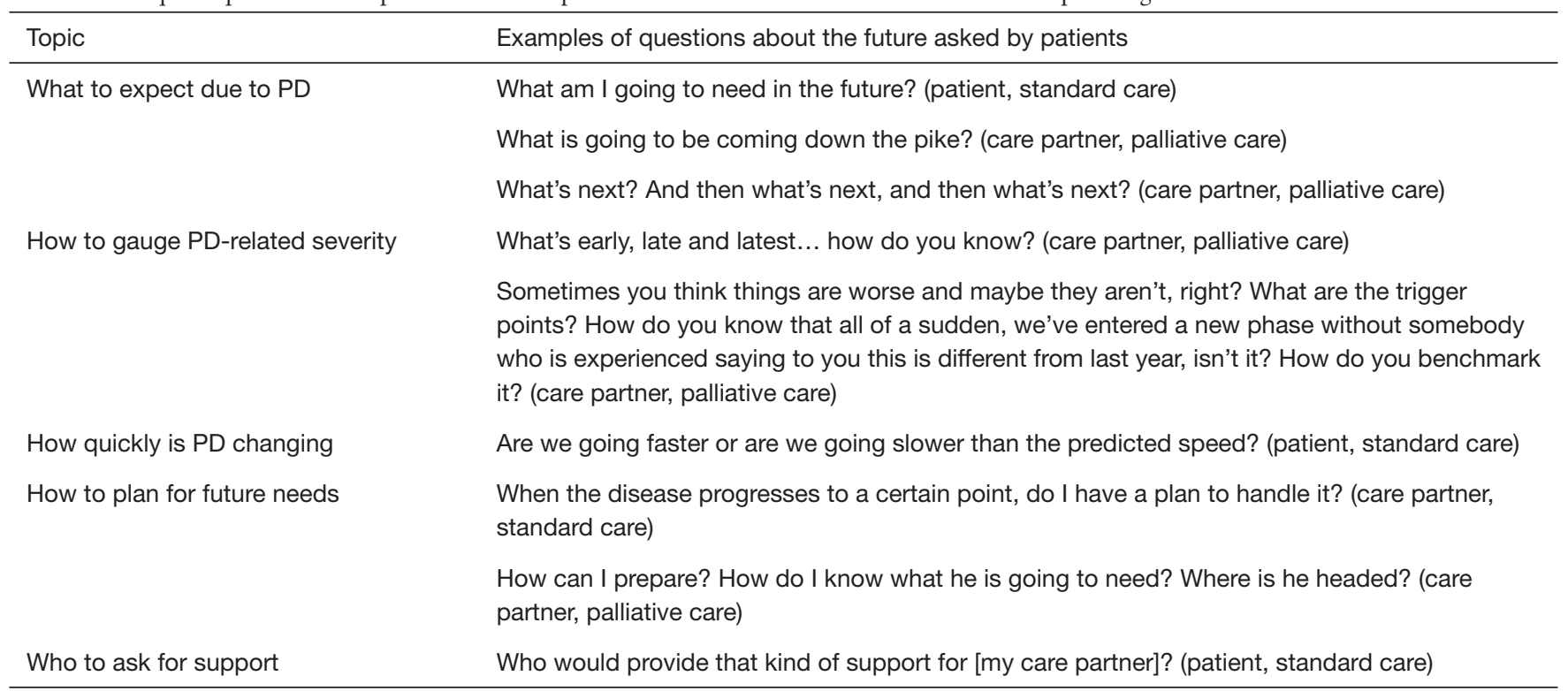

\section{Theme 2-care partner preferences for specific future planning}

Care partners also desired a comprehensive tool to help navigate future planning. In many cases, care partners were able to specifically describe their need for practical guidance to navigate the PD journey. A care partner from the palliative care arm described,

"Knowledge is power, so you need to know how to prepare yourself if you can. One of the things that I would like to know more about is the caregiving later. I was talking to a social worker that said there are real problems down the road financially if you bave to go into assisted living, and I need to know more about that to prepare financially."

Table 2 shows questions that both patients and care partners from both standard care and the palliative care arm had about the future. Common questions included what to expect, how to gauge PD-related severity, how to plan for future needs, and who to ask for support. In some cases, questions from care partners incorporated concrete options (e.g., assisted living facility $v s$. nursing home) and related considerations or limitations (e.g., finances) because they were already thinking far down the road, while patients often felt like they were trying to adjust to current physical and cognitive changes due to PD. When patients were open to discussing future planning, they could identify the change or challenge that would need to be addressed but sometimes were not able to articulate multiple options and decisions.

\section{Theme 3-PD-related life changes as opportunity for future planning and decision-making}

For the question, "What is on the roadmap?", patients and care partners identified potential "road markers" or important topics on the roadmap which could metaphorically signal PD-related life changes and a need to make certain decisions. Using the analogy of a roadmap, the road markers could be a sign that they have entered new territory to adjust to, or a sign of a fork in the road where a decision(s) needs to be made. Some life changes were identified by the patient, but more often, changes were noted by the care partner. Grouped according to the NCP Guidelines palliative care domains, Figure 2 lists common issues and concerns described by patients and care partners along their PD illness trajectory. Table S1 provides exemplary quotations from patients and care partners related to the $\mathrm{PD}$-related life changes.

Aligned with the NCP Guidelines, the two most prominent, necessary domains identified for comprehensive future planning related to 'anticipated changes in physical care' and 'social aspects of life'. Physical care examples included a desire to know how motor symptoms affected mobility, such as the ability to climb stairs or cause falls, as well as concerns broadly related to the need for assistance due to increasing disability. Future or progressive limitations in instrumental activities of daily living (e.g., medications) and self-care abilities (e.g., bathing, dressing, 


Palliative Care Domain Life Changes in Parkinson's Disease

Figure 2 Grouping of patient and care partner identified life changes in Parkinson disease and implications or decisions to consider, by palliative care domains from the National Consensus Project Clinical Practice Guidelines for Quality Palliative Care.

eating) were issues that patients and care partners wanted anticipatory guidance for. Patients and care partners described understanding their disease course by using markers to identify life changes related to how they would function in daily activities. For example, a patient in the palliative care arm said, "They said my disease will get worse and I will need walkers and wheelchairs. I'm concerned about that being a burden on my wife." Similarly, a care partner in standard care also identified road markers, "I can see that be might need some care with bathing and dressing, and also if I need to do some errands or if I want to go on a trip, we might need to have some in-home care or friends come in... it would depend on the level of progression of his disease."

As patients and care partners identified these PD-related physical changes, they described decisions and needs for helping navigate their current situation. Anticipating or experiencing limitations in daily life activities often led to concerns about where they could find more practical assistance or whether they should consider moving to a residential care facility. Managing potential changes in living arrangements was a frequent concern, and included discussions of preferences related to remaining at home, moving to a more accessible home, an assisted living facility or nursing home, and timing of moving. One care partner in the palliative care arm described the big decisions they were making about residential changes, in the midst of uncertainty about whether the patient's functional status warranted a change, saying,
"What does everybody else do? How do you know when it's time to say you need somebody in full-time evening and daytime, and when do we need to consider assisted living or nursing home? I don't know if there are any trigger points for that because he's not there yet I don't think."

Another prominent palliative care domain for future planning is social aspects of life (Figure 2). Patients and care partners described life changes related to their PD experience including professional role changes, social interaction changes, decreased driving abilities, and living situation needs. Many of these changes were influenced by underlying cognitive impairment, which affected quality of life and frequently affected the care partner's role in PD care planning. With respect to the other palliative care domains, patients and care partners described needs for guidance around life changes that related to ethical and legal issues (e.g., financial planning needs, safety concerns) and cultural aspects of care (e.g., navigating medical systems and care partner role changes), as described in detail in Supplemental Table 1.

\section{Theme 4-cues from others about "location" on the roadmap}

To answer the question "Where am I on the roadmap?", patients and care partners located themselves along the roadmap by comparing their experience to that of peers/support group members, input from healthcare professionals, and other medical changes (medications; 
objective assessments). Both patients and care partners used peers in support groups as indicators for either what is to come or what may already be progressing quickly:

"They say, 'you're doing quite well', and I think I am compared to others who bave 20 years under their belt. There were a lot of guys in our support group who are now in nursing homes because they've crossed the line and can't take care of themselves. I'm still able to do a lot of that myself. In fact, I'm going to stop driving just this year." (Patient in standard care).

Perceptions of how peers have progressed along the disease course strongly centered on social aspects of care, including seeing peers moving to assisted living, still able to continue driving, and developing dementia. Other topics like mortality and life expectancy remained unclear and difficult:

"Three other couples from our support group are pretty much in the same situation... we're all in the advanced stages of it... we're all dealing with dementia, but none of us are equipped to deal with death. Nobody has talked about it until last Novemberalmost $14 \frac{1}{1 / 2}$ years of having Parkinson's before anybody talked about death." (Care partner in palliative care).

Interactions with healthcare professionals also influenced where participants perceived themselves to be on the roadmap. Some alluded to a dissonance between cues from healthcare professionals and personal beliefs; when one care partner in the palliative arm was advised to consider assisted living, she described poignantly how this "professional roadmap" did not match her own personal roadmap of where she believed her loved one to be:

"That was the roadmap, for me to put him in a nursing home. That was the professional opinion... and it just didn't feel right to me. I don't know that there's too much value to thinking abead too far."

Tracking medications or clinical and cognitive assessments were also methods used to gauge disease progression. Care partners described monitoring changes in the type and quantity of medications as a clue of progression, yet they also described a desire for clarity surrounding what these changes to medications actually meant for disease progression. One care partner in the palliative care arm described the desire for objective measurements for PD progression, such as neuropsychological testing:

"I'd like a little more guidance about where we're at and where we're going. They do the MOCA [Montreal Cognitive Assessment] and they tell us the results but it's just a screening test. It'd be really nice if there was a psychological or a neuropsychological assessment. I know it's expensive, but it would be a snapshot of where the person is at and where they're going.
Sometimes you think things are worse and maybe they aren't, right? Or, it would be really nice to have these sorts of milestones. You sense things are changing but you don't always know for sure until you have an assessment or the doctor talks about it."

\section{Theme 5-integrating roadmaps into patient-centered PD care}

To address questions about "Who can I ask for support?", patients and care partners offered suggestions on how to integrate future planning into clinical care for PD-affected patients and care partners. Patients and care partners desired for clinicians to assess readiness to engage in future planning in a tailored and honest fashion that met patients and families where they were:

"It may have to be disclosed in bits and pieces, because I think he doesn't really want to know. When I suggested we go to the support group, he really didn't want to see what people were like in more advanced stages - it would depress bim, the different stages in disease. I do wonder, how bad will it be? What do we have to do at the latest stage when there's more disability?" (Care partner, palliative care arm).

Importantly, some had contradicting views, as this patient in the palliative care arm said: "I think it would have been helpful to have been given some idea of what was to come. It wouldn't have been such a surprise—shock, actually—if I had known what to expect." Another care partner in the palliative care arm noted the importance of addressing discrepancies in understandings of how future changes affect quality of life:

"I have asked, how can I prepare? How do I know what he is going to need, where is he headed? It was like 'well, everybody is different.' That's not particularly helpful. I need to know what it is I'm facing and the notion that it's different for everybody is understandable, but not helpful. There [bas to be] a generalization; maybe nine out of a hundred people would need this, maybe 50 out of a 100 people would need this, we find that after five years people start needing walkers and diapers and you know, whatever. It's just where the road goes."

In the context of this large outpatient neuropalliative care study, participants also identified strengths to having an interdisciplinary team-based approach, where nurses, social workers, and chaplains often also helped foster/facilitate honest discussions about the future over multiple visits.

Patients and care partners told us how a roadmap to facilitate discussions about the future was desired but would also be emotionally charged. For example, a care partner in palliative care said, "I feel like I have both an advantage and a disadvantage... I sort of know what to expect, but it makes 
me sadder now than it would if I didn't know until later." A patient in standard care said, "You can maybe find out too much and then get depressed. You kind of want to know but you don't want to know." Each of these statements demonstrates the sensitivity of having discussions about the future with PD, and the delicacy with which these discussions should be addressed by healthcare professionals.

Some patients and care partners did not wish to have a roadmap. One care partner explained: "I'm not trying to go ten years down the road, and I'm trying to look at what we can do now and enjoy every day now and not be all frantic about what we might have to do in 10 years' time" (standard care). Others described how comparisons to peers can have a potentially negative or detrimental effect:

"That's one reason I don't want to see Parkinson people, because everybody's story is a little bit different. During the course you run into these different situations, and I'm just not interested in jumping to the end to find out. I'm not going to sit down with some guy telling me exactly what's going to happen two years from now based on where I'm at." (Patient in standard care).

\section{Discussion}

Patients and care partners living with PD expressed a desire for a comprehensive tool to facilitate anticipatory guidance discussions with their clinicians about future care planning. Using the National Consensus Project Clinical Practice Guidelines for Quality Palliative Care to frame our analysis, patients and care partners emphasized physical, social, ethical/legal, emotional and cultural domains of care as they considered their questions and needs for the future. In this qualitative study, both patients and care partners described their own priorities for key PD-related life changes and implications for future planning and decision making. These priorities align with and go beyond existing medical approaches like a palliative care assessment, a comprehensive geriatric assessment, and advance care planning and goals of care discussions.

This is the first study to describe PD patient and care partner needs for future care planning through the lens of key palliative care domains. Collectively, the findings begin to suggest how researchers, patient and care partner advisors, and end-users (e.g., patients, care partners, healthcare teams) could conceptualize, refine and test a PD-specific roadmap. Given the potential for high symptom burden and distress related to multiple aspects of living with PD, future studies should formally develop a roadmap as a comprehensive shared decision-making tool that incorporates palliative care domains. The potential outcomes of an effective roadmap include patient, care partner and dyadic outcomes such as improved quality of life, receipt of needed functional assistance, relationship satisfaction and goal-concordant end-of-life care, as well as decreased care partner burden, financial burden, and time spent away from their preferred setting. Pragmatic clinical trials should understand how to implement an effective roadmap tool into clinical practice.

Findings from care partners highlighted the importance of care partner desire for information and support. Our data emphasized that care partners actively considered more than physical changes for PD patients; they consider the "whole person" and changes related to housing, driving, function, and finances. While care partners and patients asked about different aspects of road markers, they saw the value of the topics on the roadmap as opportunity to begin or continue future planning conversations as a common point of reference. Further input from patients and care partners in the design of a roadmap should identify whether there are specific variations or adaptations for unique patient or care partner versions.

Clinicians should facilitate honest, tailored conversations with patients and care partners that openly address progression, lifespan, and mortality with PD. Table 3 provides examples of clinical communication approaches on integrating anticipatory guidance about future changes and planning into clinical care. Directly discussing expectations earlier in the disease course may impact decisions and improve quality of life throughout time as PD progresses. Clinicians should also consider discussing future implications for PD, including shorter- or longerterm expectations, with patient and care partners/family when conducting clinic-based assessments such as cognitive screening (e.g., Montreal Cognitive Assessment). Our findings support participants' desire for more discussion about the interpretation of the assessments and what their results may indicate about the speed and nature of $\mathrm{PD}$ progression.

Consistent with core principles of palliative care and shared decision making, clinicians need to accurately recognize when patients or care partners are ready to discuss the future or anticipatory guidance. As PD progresses, some patients and care partners may find it difficult to discuss the future, or may struggle with the tension of wanting to know and not wanting to know. Clinicians can explore resistance or reluctance to the topics, offer support, and encourage patients and families to talk 
Table 3 Suggestions for clinician approaches to assessing patient and care partner needs related to comprehensive future planning

\begin{tabular}{|c|c|}
\hline Purpose and assessment & Example communication approaches for clinicians \\
\hline $\begin{array}{l}\text { Assess patient or care partner's perspective of } \\
\text { PD illness trajectory, and current needs }\end{array}$ & $\begin{array}{l}\text { What are you noticing about your Parkinson disease? What do you think it means in } \\
\text { terms of where you are on the roadmap? }\end{array}$ \\
\hline $\begin{array}{l}\text { Assess preferences for amount and type of } \\
\text { information, including about prognosis }\end{array}$ & $\begin{array}{l}\text { How much information would you like to discuss about what to expect next, or in the } \\
\text { future? }\end{array}$ \\
\hline Offer to discuss the issue of 'speed' & $\begin{array}{l}\text { As we think about the future, we can discuss how fast things are likely to change. We } \\
\text { can talk about how much time there is to make decisions }\end{array}$ \\
\hline $\begin{array}{l}\text { Assess care partner's current role or } \\
\text { involvement }\end{array}$ & $\begin{array}{l}\text { In relation to the (patient), has your involvement changed? Can you describe what } \\
\text { you're doing? }\end{array}$ \\
\hline $\begin{array}{l}\text { Assess current sources of support (such as } \\
\text { care partner, family, support group, community } \\
\text { organizations) }\end{array}$ & Can you tell me about who you can ask for help or support? \\
\hline
\end{tabular}

honestly. Team-based approaches with chaplains and social workers can help address and support these communications and multiple aspects of palliative care needs. This study suggests that patients and care partners who participated in neuropalliative care seemed to approach anticipatory guidance conversations with more readiness or awareness than standard care participants. Additionally, care partners might desire a more detailed discussion or independent clinical visit, if possible, within the healthcare system.

This study has several limitations. Although this study is closely grounded in patient and care partner experiences, their perspectives are highly personalized and each participant is not aware of the full range of $\mathrm{PD}$ phenotypes. An ideal shared decision-making tool would incorporate balanced and diverse input from patients, care partners, and experienced interdisciplinary healthcare team members. While attempts were made to ease the burden of the phone interview, PD-related fatigue, dysarthria, and low speech volume affected PD patients and audio quality and interview clarity for some participants. A few PD patients were able to participate with the assistance of a care partner who repeated the patient's responses. Finally, while this qualitative study is large and aimed to include as much variation in patient and care partner perspectives as possible, the study population includes predominantly white and highly educated individuals. A large majority of care partners were women. These clinical trial participants also may not be representative of persons not participating in clinical research. As a result, our understanding of the cultural aspects of care is particularly limited by the relative lack of diversity of our cohort and warrants further specific exploration.

In conclusion, patients and especially their care partners desire information for comprehensive future planning related to PD illness progression. Patients and care partners have multiple palliative care needs that they would like information about and would like the opportunity to discuss PD-related life changes. An evidence-based tool, such as a roadmap, could provide desired information to facilitate shared decision making by patients, care partners and healthcare teams, ultimately helping to improve quality of life and the experience of living with PD.

\section{Acknowledgments}

This work was possible with the assistance of our Parkinson Disease Patient and Family Advisory Council stakeholders: Fran Berry, Kirk Hall, Linda Hall, Carol Johnson, Patrick 
Maley, and Malenna Sumrall. We also thank Laura Palmer, Etta Abaca, Francis Cheung, Jana Guenther, Claire Koljack, Chihyung Park, Stefan Sillau, and Raisa Syed for their assistance as part of the larger study team. We thank Elizabeth Staton for expert assistance with manuscript preparation and review. Finally, special thanks to Dr. Betty Ferrell, of the Palliative Care Research Cooperative Caregiver Core for her expertise.

Funding: This work was supported by a Patient-Centered Outcomes Research Institute (PCORI) Award (IHS1408-20134); the Palliative Care Research Cooperative Group funded by National Institute of Nursing Research (U24NR014637); and the National Institute on Aging (K76AG054782).

\section{Footnote}

Conflicts of Interest: A Hall reports receiving reimbursement for participating as a member of the PCORI-funded Parkinson Disease Patient and Family Advisory Council. All other authors have no relevant conflicts of interest to disclose.

Ethical Statement: The authors are accountable for all aspects of the work in ensuring that questions related to the accuracy or integrity of any part of the work are appropriately investigated and resolved. This study was approved by the Institutional Review Board at each site. All participants provided written informed consent.

Disclaimer: The statements presented in this publication are solely the responsibility of the authors and do not necessarily represent the views of the Patient-Centered Outcomes Research Institute (PCORI), its Board of Governors or Methodology Committee. The contents do not represent the views of Department of Veterans Affairs or the United States Government.

\section{References}

1. Goy ER, Carter JH, Ganzini L. Needs and experiences of caregivers for family members dying with Parkinson disease. J Palliat Care 2008;24:69-75.

2. Holloway RG, Gramling R, Kelly AG. Estimating and communicating prognosis in advanced neurologic disease. Neurology 2013;80:764-72.

3. Schrag A, Hovris A, Morley D, et al. Caregiver-burden in Parkinson's disease is closely associated with psychiatric symptoms, falls, and disability. Parkinsonism Relat Disord 2006;12:35-41.

4. Bonsaksen T, Lerdal A, Fagermoen MS. Trajectories of illness perceptions in persons with chronic illness: An explorative longitudinal study. J Health Psychol 2015;20:942-53.

5. Minino AM, Murphy SL. Death in the United States, 2010. NCHS Data Brief 2012:1-8.

6. Reid WG, Hely MA, Morris JG, et al. Dementia in Parkinson's disease: a 20-year neuropsychological study (Sydney Multicentre Study). J Neurol Neurosurg Psychiatry 2011;82:1033-7.

7. Katz M, Goto Y, Kluger BM, et al. Top Ten Tips Palliative Care Clinicians Should Know About Parkinson's Disease and Related Disorders. J Palliat Med 2018;21:1507-17.

8. Ferrell BR, Twaddle ML, Melnick A, et al. National Consensus Project Clinical Practice Guidelines for Quality Palliative Care Guidelines, 4th Edition. J Palliat Med 2018. [Epub ahead of print].

9. Boersma I, Jones J, Carter J, et al. Parkinson disease patients' perspectives on palliative care needs: What are they telling us? Neurol Clin Pract 2016;6:209-19.

10. Miyasaki JM, Kluger B. Palliative care for Parkinson's disease: has the time come? Curr Neurol Neurosci Rep 2015;15:26.

11. Kluger BM, Shattuck J, Berk J, et al. Defining Palliative Care Needs in Parkinson's Disease. Mov Disord Clin Pract 2018;6:125-31.

12. Grosset KA, Grosset DG. Patient-perceived involvement and satisfaction in Parkinson's disease: effect on therapy decisions and quality of life. Mov Disord 2005;20:616-9.

13. Shimbo T, Goto M, Morimoto T, et al. Association between patient education and health-related quality of life in patients with Parkinson's disease. Qual Life Res 2004;13:81-9.

14. Butterworth K, Allam O, Gray A, et al. Providing confusion: the need for education not information in chronic care. Health Informatics J 2012;18:111-23.

15. Smith KJ, George C, Ferreira N. Factors emerging from the "Zarit Burden Interview" and predictive variables in a UK sample of caregivers for people with dementia CORRIGENDUM. Int Psychogeriatr 2019;31:437.

16. Hall K, Sumrall M, Thelen G, et al. Parkinson's Disease Foundation sponsored "Palliative Care, Parkinson's Disease" Patient Advisory Council. Palliative care for Parkinson's disease: suggestions from a council of patient and carepartners. NPJ Parkinsons Dis 2017;3:16.

17. Kluger BM, Katz M, Galifianakis N, et al. Does outpatient 
palliative care improve patient-centered outcomes in Parkinson's disease: Rationale, design, and implementation of a pragmatic comparative effectiveness trial. Contemp Clin Trials 2019;79:28-36.

18. Giles S, Miyasaki J. Palliative stage Parkinson's disease: patient and family experiences of health-care services. Palliat Med 2009;23:120-5.

19. Hughes AJ, Daniel SE, Kilford L, et al. Accuracy of clinical diagnosis of idiopathic Parkinson's disease: a clinicopathological study of 100 cases. J Neurol Neurosurg Psychiatry 1992;55:181-4.

20. Waller A, Girgis A, Currow D, et al. Development of the palliative care needs assessment tool (PC-NAT) for use by multi-disciplinary health professionals. Palliat Med 2008;22:956-64.

21. Coyne IT. Sampling in qualitative research. Purposeful and theoretical sampling; merging or clear boundaries? J Adv Nurs 1997;26:623-30.

22. Trotter RT 2nd. Qualitative research sample design and

Cite this article as: Jordan SR, Kluger B, Ayele R, Brungardt A, Hall A, Jones J, Katz M, Miyasaki JM, Lum HD. Optimizing future planning in Parkinson disease: suggestions for a comprehensive roadmap from patients and care partners. Ann Palliat Med 2020;9(Suppl 1):S63-S74. doi: 10.21037/ apm.2019.09.10 sample size: resolving and unresolved issues and inferential imperatives. Prev Med 2012;55:398-400.

23. Hsieh HF, Shannon SE. Three Approaches to Qualitative Content Analysis. Qual Health Res 2005;15:1277-88.

24. Morse JM. Critical Analysis of Strategies for Determining Rigor in Qualitative Inquiry. Qual Health Res 2015;25:1212-22.

25. Hammersley M. Assessing Quality in Qualitative Research. ESRC TLRP seminar series: Quality in Educational Research; 2005 July.

26. Carter N, Bryant-Lukosius D, DiCenso A, et al. The use of triangulation in qualitative research. Oncol Nurs Forum 2014;41:545-7.

27. Creswell JW, Poth CN. Qualitative inquiry and research design: Choosing among five approaches. Thousand Oaks: Sage publications; 2017.

28. Lum HD, Jordan SR, Brungardt A, et al. Framing advance care planning in Parkinson disease: Patient and care partner perspectives. Neurology 2019;92:e2571-9. 


\section{Supplement 1 Interview guide}

\section{Introduction and illness experience}

1. Tell me about your experience with your illness over the past year Provide an example of how it's been going. (Probe for burden, isolation, apathy, etc.)

a. Has anything become easier or improved in your life overall?

b. Has anything become more challenging over the past year? Give an example.

c. Over the past year, have relationships that are important to you changed in any way? Which relationships, and how/ in what ways?

d. How satisfied are you with your care relating to Parkinson disease? Can you elaborate?

i. Was anything missing?

ii. What would be helpful from providers?

iii. What additional services could help improve your quality of life?

2. Some people have told us that there are some things they don't always feel comfortable sharing in medical visits. Have there been times when you held something back from your doctor or didn't share with them or show them something? Why?

a. Patients: Have there been times when you did this with a care partner or loved one? Why? Probe for burden, shame, independence, etc.

i. What could your medical team do to help this? Or what could be a good strategy where you would feel safe to talk honestly about this with loved ones or providers?

b. Care partners: Have you ever held back sharing something with the doctor about the patient's condition? If so, why?

i. What do you think could be a good strategy to encourage you to talk honestly about your concerns?

c. I know you were randomized to the ___ arm. How is your experience different in the ___ arm of the study, compared to your previous experiences with neurology care, when it comes to sharing information with providers? (Does this happen with PCP and not study neurologist, vice versa?)

d. Patients: Do you normally go to your visits by yourself or does someone go with you? Have you ever met with the doctor without your care partner? Is there value in being seen as a couple or an individual?

i. If yes-how did it benefit you, what did you accomplish?

ii. If no-what do you think of that?

e. Care partners: Have you ever met with the doctor without your partner or loved one? Is there value in being seen as a couple or an individual?

i. If yes-how did it benefit you, what did you accomplish then?

ii. If no-what do you think of that?

f. How could the medical team ask about your needs as a couple versus your needs as an individual?

i. How can we do more for you as a "paired" relationship? (as a couple, as a twosome)

g. What additional services or support could your medical team provide to care partners? How can we do more for care partners?

3. We are specifically interested in your thoughts about the future.

a. What is most important to you when thinking about the future?

i. Have you talked about this with anyone? Who with, about what?

b. What are you most concerned (worried about) about for the future? 


\section{Advance care planning (ACP) or 'Goals of Care' (Canada) section}

4. Have you thought about what you want your life or situation to look like as you near the end of life, or when you can tell time is short?

a. What did you decide on? What decisions did you make? Probe for specific things.

b. How did you decide what is important to you?

5. Can you tell me about any prior experiences you (or your loved one) have had with future medical planning or advance care planning?

a. How did it come up? With who?

b. Did you complete documents, have a discussion, etc.?

i. Tell me about the documents you filled out.

ii. What are the goals of this document?

iii. What are you hoping this document does?

iv. Do you have any concerns about the document?

v. Do you feel that your wishes will be followed? Why or why not?

1. Probe for discussions with family, following through on wishes, how well was the discussion received? Will they follow through?

c. Did you do anything after this discussion or after completing these documents?

i. Share with anyone, make copies?

d. How comfortable were you in discussing ACP?

e. IF NO EXPERIENCE: Why? Barriers? What would be helpful to overcome this? Who would you want to discuss this with?

6. How important is it to you to take actions related to future medical planning, such as talking about what you want or writing it down? What is the value of ACP to you?

a. What do you think ACP adds to your life (having had these discussions, OR NOT)? Examples of how your life or your activities look different because of this?

b. What challenges have you experienced related to this type of planning?

c. Has anything changed over time, as far as your values and preferences?

d. What is the risk in not engaging with ACP?

7. Have you ever received ACP educational materials (goals of care in Canada) from a doctor or someone else? Has a medical provider brought up these discussions?

a. Where else have you gotten information from? (lawyer, website, support group)?

b. What type of services or information could be provided to help you plan for your future medical care?

\section{[The remaining questions are for participants from any setting, US or Canada]}

8. How do you think ACP should be introduced to people with Parkinson disease?

a. Who should initiate the discussion?

b. Who should all be involved in the conversation?

c. When should ACP discussions happen- at what point in the illness journey?

d. What are your thoughts about discussing this in group medical visits, where you would participate with other patients, care partners and medical providers to discuss common concerns related to Parkinson disease? 
9. Now, I'd like to ask specifically about the potential for memory loss or dementia related to Parkinson disease.

a. Can you tell me how you think about potential memory loss or inability to make decisions for yourself (or for your patient if care partner)? Probe for concerns

b. How have memory concerns affected (or not) your future medical planning?

c. Can you describe your experiences talking about current memory changes or future memory loss concerns with your doctor?

i. Are you able to talk about it with your loved ones?

d. What has been helpful to these discussions? What could be better/different?

10. For care partners: How involved did you want to be in the ACP decision making process? Why?

a. How important do you feel it is to know the treatment preferences of the person you care for? Why?

b. How confident are you in your understanding of what they want?

c. What kind of things are missing that would help care partners be more involved in ACP processes?

11. Some people have told us they would like to have a 'roadmap' of their journey with Parkinson disease, which would better prepare them for what to expect down the road. What do you think of this idea?

a. What would you like to see on the roadmap? What 'markers?' Actionable items

\section{Mortality myth}

12. I have a final question about the future related to Parkinson disease. What is your current understanding about how Parkinson impacts mortality?

a. Has your neurologist talked with you about how Parkinson disease affects life span?

b. What were you told?

c. Are you someone who wants to know details about how your disease impacts mortality?

i. How do you think your care matches this, or doesn't?

\section{Closing questions}

13. Given this is part of a research study, what do you think are the most important or valuable outcomes we should measure? (e.g., quality of life, not having to worry about the future, feeling of support from healthcare team, control over health decisions, outlook on disease, care partner stress or support?)

a. In other words, what is the most important thing we should understand about your illness journey? What would signify improvement to you?

b. What makes that important to you?

c. You may remember having completed survey questions, some of which asked about burden and depression. What type of questions do you think we should be asking that capture what is valuable to you (on surveys)?

14. Anything else you want to add that we have not covered in our discussion today? Thank you. 


\begin{tabular}{|c|c|}
\hline Life changes & Exemplar quotation \\
\hline \multicolumn{2}{|c|}{ Palliative care domain: physical aspects of care } \\
\hline $\begin{array}{l}\text { Motor symptoms and } \\
\text { mobility }\end{array}$ & $\begin{array}{l}\text { Right now, the master bedroom is on the second floor. I'm } \\
\text { getting a little nervous going up and down the stairs. }\end{array}$ \\
\hline $\begin{array}{l}\text { Household ability changes } \\
\text { (iADLs) }\end{array}$ & $\begin{array}{l}\text { That's why I can't look after my husband at home, [that is] why } \\
\text { he had to go to long term care, because he was too ill to be at } \\
\text { home. His medical needs are too heavy. He gets medication } 11 \\
\text { times a day. }\end{array}$ \\
\hline \multirow[t]{2}{*}{$\begin{array}{l}\text { Self-care ability changes } \\
\text { (ADLs) }\end{array}$} & $\begin{array}{l}\text { He can fix cereal, but l'm looking forward to a time when he } \\
\text { can't do that, and I'm struggling. }\end{array}$ \\
\hline & $\begin{array}{l}\text { That [roadmap] would help me a lot [for] support options at } \\
\text { night... if I reach a point where I need help during the night, } \\
\text { how is that going to happen? Certainly, all of this doesn't relate } \\
\text { directly to my care, but it does relate to her support (care } \\
\text { partner). }\end{array}$ \\
\hline
\end{tabular}

\section{Palliative care domain: psychological aspects of care}

Anxiety, depression

Isolation

I don't know what the warning signs are that his depression is taking a turn for the worst or if he's miserable because he can't do things.

When do you tell them they can't go out in the community on their own? He made the decision not to drive on his own Some of those other decisions are hard; he wants to take a bus somewhere and he can't. He would get lost.

Palliative care domain: social aspects of care

Professional role changes

Cognitive decline at some point is going to become more than inconvenient. I can no longer do the job that I used to do being a tour director. My memory can't support that anymore.

Social interaction changes I've noticed [with] conversations I try to have with people. I walk around the block each day and five years ago we'd chat about each other. Now, they have learned that I'm hard to hear or that I'm hard to listen to. ... The neighbors have learned to turn away from me because it's more of an effort to talk... that reduces my social ability in their lives.

Driving ability

In the early days, they'd say that you'd have one side that was worse off than the other, and then I knew I was in this stage when both sides of my body were going, so it's almost like a marker for when I can drive. I can still drive, but not all day..

Living situation needs Assisted living [should be on the roadmap] and what it's going to cost. I can still do [stairs] but I'm thinking we need to start looking for a place where everything is on one floor. Should we do it now and then have to move again when we go into assisted living, or do we just start looking at assisted living?

Palliative care domain: cultural aspects of care

Navigating medical systems It's a complex issue how to manage all the things that a person in society would have to take care of... the medical system is so complex that [care partners] spend half the time talking about payments and managing my issues with the insurance.

Care partner role changes

If it gets to the stage where he can't get in and out of bed himself, then I'm going to need a lot of home care. I'm going to need someone to come every day probably because I certainly can't lift him.

Palliative care domain: end of life aspects of care

Physician-assisted death

I may get to the point where I can't live alone. Well that's the point in time when I start looking at physician assisted death.

Palliative care domain: ethical and legal aspects of care

Financial planning needs

Safety concerns
Financial planning would be crucial to some people with Parkinson: a list of resources and what it's going to cost and what's available.

I'm realizing the needs are going to be more than physical, and safety is going to be an issue, and how to determine what's safe for him and what's safe for the family. It's all very tricky on a day to day basis... when do you tell a person they can't do something around the house anymore because it would be unsafe for them or for the family? $\begin{array}{ll}\text { Patient in } & \text { Residential } \\ \text { standard care } & \text { changes }\end{array}$

Care partner in Care partner standard care resources and planning (e.g., home care; respite)

Care partner in Care partner palliative care resources and Patient in planning (e.g. standard care home care; facility care)

Care partner in palliative care

Counseling, support, socialization

Care partner in Community palliative care resources

Patient in

Professional retirement

Counseling, support, socialization

Patient in standard care

Driving retirement

Patient in

Residential standard care changes

Patient in

Care partner availability and willingness for care coordination

Care partner in standard care

Care partner availability and willingness for care coordination

Patient in standard care

Comprehensive advance care planning

Patient in

Financial standard care counseling

Care partner in palliative care

Education, support, care partner resources and planning 